\title{
ANÁLISE DE PATOLOGIAS EM PAVIMENTOS FLEXÍVEIS NA CIDADE DE SALVADOR, BAHIA.
}

\author{
BARROS, MARCELO \\ Estudante \\ Faculdade Área 1 Wyden \\ Bahia; Brasil \\ mvbarros.97@gmail.com
}

\author{
MARIANI, BRUNA \\ Engenheira Civil \\ Faculdade Área 1 Wyden \\ Bahia; Brasil \\ brunabmariani@gmail.com
}

\begin{abstract}
RESUMO:
A investigação dos principais mecanismos de deterioração e o estabelecimento de manutenções periódicas dos pavimentos flexíveis são atividades essenciais para a eficácia de seu desempenho e para o alcance de sua vida útil projetada. O desempenho de um pavimento é considerado o índice de gravidade global com que o mesmo atende as funções que lhe são impostas ao longo de sua vida de serviço. A análise do desempenho de um pavimento busca identificar sua condição atual, possibilitando definir as ações e intervenções a serem adotadas. Neste contexto, o objetivo deste trabalho consiste em analisar por meio de um estudo de caso as patologias existentes nas vias da cidade de Salvador-BA, especialmente, na Via Regional, que inicialmente foi necessário um projeto geométrico da via, terraplanagem e por fim o de reforço estrutural, baseados em dados coletados a partir de estudos realizados pelas empresas responsáveis pela obra, de recuperação da via. Foram investigados diversos tipos de defeitos, relacionando suas principais causas e intervenções a serem adotadas, e por fim, elaborando projetos de reconstrução de todo o pavimento, desde o subleito até o revestimento.

Palavras-chave: Pavimentos flexíveis, Pavimento asfáltico, Patologias, Defeitos.
\end{abstract}

\begin{abstract}
Investigation of the main deterioration mechanisms and the establishment of periodic maintenance of flexible pavements are essential activities for the efficiency of its performance and the reach of its projected useful life. The performance of a floor is considered the overall severity index with which it fulfills the functions imposed on it during its service life. The performance analysis of a pavement seeks to identify its current condition, making it possible to define the actions and interventions to be adopted. In this context, the objective of this work is to analyze through a case study the pathologies existing in the roads of the city of Salvador-BA, especially in the Regional Road, which initially required a geometric design of the road, earthmoving and finally the structural reinforcement, based on data collected from studies carried out by the companies responsible for the work, of road recovery. Several types of defects were investigated, relating their main causes and interventions to be adopted, and finally, elaborating projects for reconstruction of the entire pavement, from the subgrade to the coating.
\end{abstract}

Keywords: Flexible floors, Asphalt pavement, pathologies, Defects.

\section{INTRODUÇÃO}

Os pavimentos flexíveis são compostos por uma camada de revestimento, obtida a partir de materiais betuminosos ou asfálticos, que sobrepõe e transfere as tensões do tráfego para as camadas de base, e sub-base, até chegar no subleito respectivamente. Geralmente suas camadas são compostas por materiais granulares, e na última camada que é o subleito, se faz um reforço para melhorar sua resistência diante às tensões recebidas, evitando ruptura súbita e sim degradação funcional e estrutural devido ao tráfego.

No Brasil, a mais utilizada forma de transporte de bens e pessoas é feita pelo modal rodoviário, sendo assim, é necessário que as estradas e rodovias sejam economicamente viáveis, que tenham qualidade e garantam segurança e conforto para todos os usuários. Contudo, a precariedade de rodovias no Brasil devido à falta de manutenção preventiva, se tornou uma situação comum, gerando maiores custos e intervenções imediatas. 
O reparo das rodovias é feito a partir de inspeções que avaliam a gravidade do defeito e sua prioridade e método de intervenção.

Os defeitos que os pavimentos apresentam durante a sua vida útil, podem ser avaliados de forma objetiva, mas é necessária uma melhor classificação dos defeitos para que se possa avaliar de forma coerente as características específicas para cada tipo de fissura, deformação e degradação do material asfáltico.

Com o intuito de apresentar os diversos tipos de defeitos que surgem nos pavimentos flexíveis, além de suas causas e métodos de reparo, este estudo visa através de uma revisão de literatura apresentar as classificações dos defeitos, definindo o tipo, severidade e extensão de cada um. Também demostrando medidas preventivas, evitando assim altos custos com manutenções corretivas.

\section{METODOLOGIA}

A presente pesquisa foi desenvolvida a partir de duas etapas metodológicas. Inicialmente, um estudo bibliográfico foi realizado, acerca das principais patologias encontradas nos pavimentos flexíveis e suas possíveis causa e soluções. De caráter qualitativo, a coleta de dados foi obtida por meio de artigos, dissertações, teses, e publicações em revistas e periódicos, que possibilitaram o levantamento da base conceitual referente ao tema.

O trecho da Via Regional (Figura 01), foi selecionado devido ao fato de ter uma grande quantidade de defeitos em toda a sua extensão, onde toda a base de dados foi conseguida através de artigos, literaturas, e o relatório técnico das empresas responsáveis pela obra.

Inicialmente, foi necessário um projeto de terraplanagem em alguns trechos da Via Regional, desenvolvido a partir do projeto geométrico, procurando-se soluções adaptadas às condicionantes locais, especialmente, as cotas das edificações existentes e do tipo do terreno, visando obter-se um mínimo de movimentos de terras.

O intuito desse projeto de terraplanagem é o reforço estrutural do próprio subleito obedecendo as especificações, a fim de se obter um CBR (Índice de Suporte Califórnia, que é um ensaio utilizado é um parâmetro empírico utilizado no dimensionamento além de permitir descobrir o índice de expansibilidade do solo, quando o corpo de provas é submerso em água) mínimo de $10 \%$, compatível com o dimensionamento do pavimento. Tendo uma espessura mínima de $0,20 \mathrm{~m}$ na sua última camada.

Figura 01: Representação da Via Regional no mapa

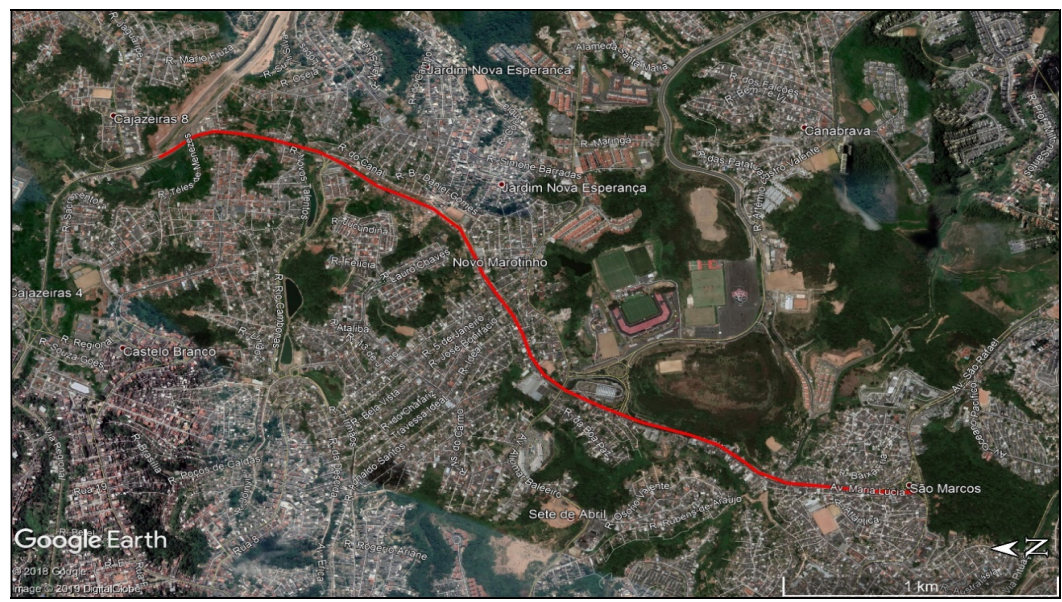

FONTE: Adaptado do Google Earth (2019) 
Na segunda etapa, um estudo de caso foi desenvolvido por meio da análise de uma obra de requalificação de rodovias na cidade de Salvador-BA, com o intuito de verificar as principais patologias encontradas em uma rodovia de análise, suas causas e intervenções a serem adotadas. A obra está localizada na Via Regional, onde serão requalificados 3,4 km, partindo da Rotatória de São Marcos, até a Avenida 29 de março, utilizando a técnica de recapeamento asfáltico. As distâncias dos trechos analisados estão apresentadas na Tabela 01.

Tabela 01 - Comprimento dos trechos do Projeto Geométrico

\begin{tabular}{|l|l|}
\hline TRECHO DO PROJETO & COMPRIMENTO (m) \\
\hline Via Regional & 3003,96 \\
\hline Via - 01 da Praça & 105,61 \\
\hline Via - 02 da Praça & 93,74 \\
\hline Via de entrada a Av. 29 de Março & 204,46 \\
\hline TOTAL & $\mathbf{3 4 0 7 , 7 7}$ \\
\hline
\end{tabular}

FONTE: Resultado da pesquisa, 2019

O Projeto de Pavimentação busca definir a estrutura a ser apoiada sobre o greide de terraplenagem, ou outro pavimento em condições de atender às características de trafegabilidade com conforto, que envolve a obtenção de vários parâmetros ligados ao tráfego. O primeiro parâmetro é definido por seu número "N" que é o número de repetições (ou operações) dos eixos dos veículos, equivalentes a solicitações do eixo padrão rodoviário de 8,2 tf durante o período considerado de vida útil do pavimento. Definindo-se assim o número característico $\mathbf{N}$ de Projeto, onde parâmetros e características funcionais das vias estabelecidos pela Instrução de Projeto da Prefeitura Municipal de São Paulo (IP02/2004-PMSP - Classificação de Vias) através da formula:

$$
\mathrm{Nn}=365 \times \text { TMDA } \times \text { FV } \times \text { FR } \times \text { FD }
$$

Onde:

365 = Número de dias de um ano

TMDA $=$ Tráfego Médio Diário Anual na rodovia

$\mathrm{FV}=$ Fator de Veículos

$\mathrm{FR}=$ Fator Climático Regional

$\mathrm{FD}=$ Fator Direcional

A Via Regional está classificada como via Coletora Principal com Tráfego meio pesado, cujo $\mathbf{N}$ utilizado para o dimensionamento foi de $\mathbf{2 , 0 0} \times \mathbf{1 0}^{\mathbf{6}}$, de acordo com os estudos característicos, feitos na própria via. De acordo com a Tabela 2. 


\begin{tabular}{|c|c|c|c|c|c|c|c|}
\hline \multirow{2}{*}{$\begin{array}{l}\text { FUNÇÃO } \\
\text { PREDOMINAN } \\
\text { TE }\end{array}$} & \multirow{2}{*}{$\begin{array}{l}\text { TRÁFE } \\
\text { GO } \\
\text { PREVIS } \\
\text { TO }\end{array}$} & \multirow{2}{*}{$\begin{array}{l}\text { VIDA } \\
\text { ÚTIL DE } \\
\text { PROJET } \\
\text { O } \\
\text { (ANOS) }\end{array}$} & \multicolumn{2}{|c|}{\begin{tabular}{l}
\multicolumn{2}{l}{ VOLUME INICIAL } \\
FAIXA \\
CARREGADA
\end{tabular}} & \multirow{2}{*}{$\begin{array}{l}\text { EQUIVALE } \\
\text { NTE POR } \\
\text { VEÍCULO }\end{array}$} & \multirow{2}{*}{$\mathbf{N}$} & \multirow{2}{*}{$\begin{array}{l}\mathbf{N} \\
\text { CARACTERÍS } \\
\text { TICO }\end{array}$} \\
\hline & & & $\begin{array}{l}\text { VEÍCULO } \\
\text { LEVE }\end{array}$ & 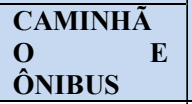 & & & \\
\hline Via Local & Leve & 10 & $\begin{array}{ll}100 & \mathrm{a} \\
400 & \end{array}$ & 4 a 20 & 1,50 & $\begin{array}{l}2,70 \times 10^{4} \mathrm{a} \\
1,40 \times 10^{5}\end{array}$ & $10^{5}$ \\
\hline $\begin{array}{l}\text { Via Coletora } \\
\text { Secundária }\end{array}$ & Médio & 10 & \begin{tabular}{ll|}
401 & $\mathrm{a}$ \\
1.500 & \\
\end{tabular} & 21 a 100 & 1,50 & $\begin{array}{l}1,40 \times 10^{5} \text { a } \\
6,80 \times 10^{5}\end{array}$ & $5,00 \times 10^{5}$ \\
\hline $\begin{array}{l}\text { Via Coletora } \\
\text { Principal }\end{array}$ & $\begin{array}{l}\text { Meio } \\
\text { Pesado }\end{array}$ & 10 & $\begin{array}{ll}1.501 & \mathrm{a} \\
5.000 & \\
\end{array}$ & 101 a 300 & 2,30 & $\begin{array}{l}1,40 \times 10^{6} \mathrm{a} \\
3,10 \times 10^{6}\end{array}$ & $2,00 \times 10^{6}$ \\
\hline Via Arterial & Pesado & 12 & $\begin{array}{l}5.001 \text { a } \\
10.000\end{array}$ & \begin{tabular}{ll|}
301 & $\mathrm{a}$ \\
1.000 & \\
\end{tabular} & 5,90 & $\begin{array}{l}1,00 \times 10^{7} \text { a } \\
3,30 \times 10^{7}\end{array}$ & $2,00 \times 10^{7}$ \\
\hline $\begin{array}{l}\text { Via Arterial } \\
\text { Principal/Expre } \\
\text { ssa }\end{array}$ & $\begin{array}{l}\text { Muito } \\
\text { Pesado }\end{array}$ & 12 & $>10.00$ & $\begin{array}{ll}1.001 & \mathrm{a} \\
2.000 & \end{array}$ & 5,90 & $\begin{array}{l}3,30 \times 10^{7} \mathrm{a} \\
6,70 \times 10^{7}\end{array}$ & $5,00 \times 10^{7}$ \\
\hline \multirow{2}{*}{$\begin{array}{l}\text { Faixa } \\
\text { Exclusiva de } \\
\text { Ônibus }\end{array}$} & $\begin{array}{l}\text { Volume } \\
\text { Médio }\end{array}$ & 12 & - & $<500$ & - & $3,00 \times 10^{6}$ & $10^{7}$ \\
\hline & $\begin{array}{l}\text { Volume } \\
\text { Pesado }\end{array}$ & 12 & - & $>500$ & - & $5,00 \times 10^{7}$ & $5,00 \times 10^{7}$ \\
\hline
\end{tabular}

FONTE: IP-02/2004 CLASSIFICAÇÃO DAS VIAS (PMSP)

Com isso a via Regional, é considerada como uma via coletora de grande importância dentro da rede viária da cidade de Salvador, tem por objetivo facilitar o tráfego de veículos entre vários bairros que se encontram ao longo deste trecho sendo que a via é destinada principalmente ao trânsito de veículos comerciais.

As áreas ocupadas pelo trecho a ser requalificado da Via Regional apresentam um terreno ondulado com pouca declividade, com largura da pista de rolamento variando entre 11 e 12 metros. Logo, a velocidade diretriz da rodovia é $60 \mathrm{~km} / \mathrm{h}$. A velocidade diretriz é representada na tabela 3.

Tabela 3 - Velocidade Diretriz

\begin{tabular}{|c|c|c|c|}
\hline \multirow{2}{*}{$\begin{array}{c}\text { CLASSE } \\
\text { DE } \\
\text { PROJETO }\end{array}$} & \multicolumn{3}{|c|}{ VELOCIDADE DE PROJETO $(\mathrm{km} / \mathrm{h})$} \\
\cline { 2 - 4 } & PLANA & ONDULADA & MONTANHOSA \\
\hline 0 & 120 & 100 & 80 \\
\hline I & 100 & 80 & 60 \\
\hline II & 100 & 70 & 50 \\
\hline III & 80 & 60 & 40 \\
\hline IV & $80-60$ & $60-40$ & $40-30$ \\
\hline
\end{tabular}

Fonte: Manual de Projeto Geométrico de Rodovias Rurais (DNER, 1999)

\section{REFERENCIAL TEÓRICO}

\subsection{Pavimento Flexível}

De acordo com Bernucci et al. (2008), pavimentos flexíveis, em geral associados aos asfálticos, são aqueles em que o revestimento é composto por uma mistura constituída basicamente de agregados e ligantes asfálticos. É formado por quatro camadas principais: revestimento, base, sub-base e reforço do subleito. O revestimento asfáltico pode ser 
composto por camada de rolamento, em contato direto com as rodas dos veículos e por camadas intermediarias ou de ligação. Dependendo do tráfego e dos materiais disponíveis, pode-se ter ausência de algumas camadas. As camadas da estrutura repousam sobre o subleito, ou seja, a plataforma da estrada termina após a conclusão dos cortes e aterros. As camadas de base, sub-base e reforço do subleito são de grande importância estrutural. Limitar as tensões e deformações na estrutura do pavimento, por meio da combinação de materiais e espessura das camadas constituintes, é o objetivo da mecânica dos pavimentos (BERNUCCI et al., 2008).

$\mathrm{O}$ autor supracitado ainda afirma que o dimensionamento dos pavimentos é determinado pelas espessuras das camadas e o tipo dos materiais a serem utilizados. As principais camadas são apresentadas na Figura 2.

Figura 2- Representação das camadas do solo.

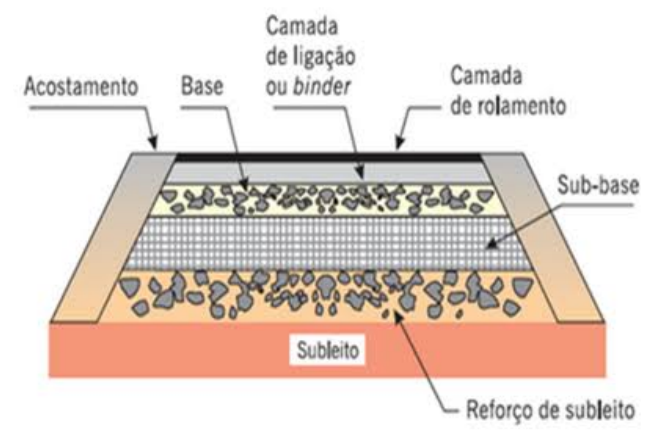

Fonte: Bianchi, 2008

\section{- Revestimento}

É uma camada impermeabilizante, composta pela combinação de agregado mineral e material betuminoso, que suporta e transmite as cargas aplicadas pelos veículos, para as camadas inferiores. E tem como função melhorar a superfície de rolamento, garantindo as condições de conforto e segurança, resistindo ao desgaste.

- Camada de ligação

É a camada intermediária, entre o revestimento e a base, garantindo uma melhor aderência do revestimento além de nivelar o pavimento.

- Base

É a camada estrutural mais importante, sendo construída por materiais estabilizados granulometricamente ou quimicamente, através do uso de aditivos (cal, cimento, betume). E sua finalidade é resistir e distribuir os esforços provenientes da ação do tráfego, atenuando a transmissão destes esforços às camadas subjacentes.

- Sub-base

Camada utilizada para reduzir a espessura da base, onde irá resistir às cargas transmitidas pela base, além de drenar as infiltrações e controlar a ascensão da água.

- Reforço do subleito

O reforço é a camada necessária quando o subleito possui baixa capacidade de carga e também serve para reduzir a espessura da sub-base. 
- Subleito

Camada que possui espessura variável, onde em alguns trechos podem não ser utilizados, e sempre que possível deve ser executada em aterro (Greco).

Durabilidade

A principal exigência quanto ao bom desempenho de materiais de pavimentação está diretamente ligada à sua vida útil. Este período é normalmente definido pelo contratante ou fixado pelo projetista em função das características do Sistema Viário Proposto ou Existente, que segue a Instrução de Projeto da Prefeitura Municipal de São Paulo (IP-02/2004PMSP - Classificação de Vias), os valores usualmente utilizados variam conforme indicado na Tabela 4, a seguir.

Tabela 4 - Vida útil do projeto de acordo com a tipologia da via.

\begin{tabular}{|c|c|}
\hline $\begin{array}{c}\text { CONDIÇÃO DE UTILIZAÇÃO DO } \\
\text { SISTEMA VIÁRIO }\end{array}$ & $\begin{array}{c}\text { VIDA ÚTIL EM } \\
\text { ANOS }\end{array}$ \\
\hline Acessos Locais & 5 \\
\hline Vias Locais & 10 \\
\hline Vias Coletoras & $\mathbf{1 0}$ \\
\hline Vias Arteriais & 12 \\
\hline
\end{tabular}

Fonte: IP-02/2004 CLASSIFICAÇÃO DAS VIAS (PMSP)

Por conta da Via Regional ser considerada uma Via coletora, o projeto adotou o período de vida útil de 10 anos, porém, para que a Vida Útil prevista no projeto seja atingida é necessário que o pavimento seja executado conforme o projeto e que, periodicamente, seja promovida a inspeção e realizada a manutenção da mesma pelos Órgãos competentes, de acordo com as exigências do DNIT (2010).

\subsection{Principais defeitos}

Devido os pavimentos flexíveis sofrerem muito com aplicação de carga, exposição às intempéries, ações humanas e da natureza, acabam apresentando defeitos e patologias, que pode ter características simples ou complexas.

- Fissuras: São aberturas no revestimento asfáltico com extensão de no máximo $30 \mathrm{~cm}$, que inicialmente não afeta funcionalmente nem estruturalmente a rodovia. Estas aberturas podem se posicionar de forma longitudinal, transversal ou obliquamente e pode ser vista a uma distância de até 1,5 m (DNIT, 2003).

- Trincas transversais: São fissuras evoluídas no sentido perpendicular ao eixo da via. De acordo com Pinto (2003), as trincas transversais se agravam pela penetração de água, pelo enfraquecimento das camadas inferiores, eventual bombagem e formação de ninhos. Este defeito ocorre devido a degradação frequente do pavimento flexível. Com a tração por flexão gerada pela passagem repetida dos veículos a fadiga dos materiais utilizados nas camadas betuminosas como se torna uma das principais causas.

- Trincas longitudinais: Essas tricas são caracterizadas quando for uma trinca isolada que apresenta direção predominantemente paralela ao eixo da via. Quando seu comprimento for até $100 \mathrm{~cm}$ é denominada trinca longitudinal curta. Quando a extensão for superior a $100 \mathrm{~cm}$ denomina-se trinca longitudinal longa (DNIT, 2003). 
Geralmente tendem a aparecer isoladas e costumam ser paralelas ao eixo do pavimento. De acordo com Silva (2008), podem ser causadas devido à má execução da junta de construção, reflexão de trincas, assentamento da fundação, retração do revestimento de asfalto ou estágio inicial de fadiga.

- Trinca em malha tipo "couro de jacaré": O trincamento em malha, conhecido como couro de jacaré apresenta características específicas, em que são representadas inicialmente como uma série de fendas longitudinais paralelas, remetendo ao estágio avançado de fadiga. De acordo com Pinto (2003), sua degradação está associada à insuficiente capacidade de carga do pavimento e inicialmente limita-se a áreas sujeitas a cargas repetidas pela passagem sucessiva de veículos.

A origem das fissuras ocorre de forma isolada, contudo, com o passar do tempo, acabam se interligando e apresentando o aspecto de pele de jacaré. Caso continue se agravando pode ocorrer o desprendimento de blocos e formação de ninhos.

- Trinca em malha tipo "bloco": Essas trincas possuem configuração próxima a de um retângulo e ocorrem devido à uma retração na parte do revestimento asfáltico e também pelas variações diárias de temperatura segundo Silva (2008). Este tipo de trinca indica que o pavimento teve um forte endurecimento devido a sua oxidação ou volatização dos maltenos (que são constituídos de compostos saturados, compostos aromáticos e resinas, que são solúveis no n-hepnano ou éter). Os tornando menos flexíveis.

As trincas neste caso não estão relacionadas com o tráfego, as mesmas podem aparecer em qualquer lugar, mesmo não tendo muito fluxo de veículos.

- Afundamento plástico: O afundamento plástico é causado pela ação das cargas dos pneus que passam repetidas vezes.Réus, Silva Júnior e Fontenelle (2016). O DNIT (2003) explica que, este fenômeno se trata do afundamento causado pela fluência plástica de uma ou mais camadas do pavimento ou do subleito, acompanhado de solevamento.

Quando ocorre em extensão de até 6 metros é denominado afundamento plástico local; quando a extensão for superior a 06 metros e estiver localizado ao longo da trilha de roda é denominado afundamento plástico da trilha de roda (SILVA, 2008).

- Afundamento de consolidação: De acordo com Silva (2008), o afundamento de consolidação existe pelo fato de a consolidação diferencial ocorrer em camadas do pavimento e/ou do subleito (Figura 09). Quando tem até 6 metros de extensão, são chamados de consolidação local; quando maiores que 6 metros, consolidação na trilha. Sendo causado também pela ação das cargas dos pneus dos veículos que transitam na via.

- Ondulação ou Corrugação: Popularmente conhecidos como "costela de vaca", são caracterizadas por deformações e ondulações transversais ao eixo da via, que geralmente ocorrem no revestimento superficial sendo a camada de desgaste. Segundo Pinto (2003), esta deformação é devido à uma má distribuição do ligante (causadas por deficiências construtivas do pavimento), em camadas de concreto betuminoso em que ocorra o arrastamento da mistura por excessiva deformação plástica ou resultante da deformação da fundação.

- Escorregamento: O descolamento do revestimento ocorre devido à baixa resistência da massa asfáltica ou a falta de aderência entre a camada de revestimento e a camada subjacente, resultando na formação das trincas, em forma de meia-lua, no pavimento. Segundo Silva (2008), os veículos são os responsáveis por sua formação quando causam deslizamento ou a deformação da massa asfáltica na área de frenagem. 
- Exsudação: De acordo com o DNIT (2003), quando acontece a dilatação no calor, a exsudação do asfalto ocorre para a superfície, onde o pavimento encontra dificuldade de ocupar espaço devido ao pequeno volume de vazios ou então ao excesso de ligante.

Para Pinto (2003), a causa deste defeito pode estar associada à uma deficiente formulação da mistura betuminosa da camada de desgaste, excesso de ligante ou pela viscosidade reduzida do mesmo, por contaminação através de rega de colagem excessiva ou por inadequada dosagem de agregados, tudo isto associado a condições severas de tráfego e temperaturas elevadas.

- Desgaste: O desgaste tem como efeito, o arrancamento do agregado do pavimento, transpassando uma aspereza na superfície do revestimento e é provocado pelos esforços tangenciais que o tráfego causa.

- Buraco: Surge através da evolução de outras patologias, como as fendas, principalmente a do tipo "couro de jacaré", afundamentos, desgastes, falta de aderência entre as camadas e a desagregação da camada de desgaste. A água um agravante severo para o pavimento, pois se acumula nas trincas e adianta o processo de degradação do revestimento, denominado "stripping".

- Remendo: Segundo Pinto (2003), o Remendo não constitui uma patologia, indicam zonas com evoluções prematuras relativamente ao restante pavimento, sendo classificadas de acordo com a sua qualidade de execução e em função do seu estado.

\subsection{Métodos de reparo}

- Recuperação de Fissuras / Trincas: Para fazer a recuperação de fissuras e trincas, sejam as transversais, longitudinais, "couro de jacaré” ou "bloco", pode ser utilizada a técnica de capa selante, tratamento superficial, lama asfáltica e microrrevestimento asfáltico, seguindo instruções de ROCHA (2010). Segundo Yoshizane (2005, p.8, apud ROCHA, 2010), capa selante é a atividade que consiste na aplicação apenas de ligante asfáltico ou de ligante com agregados sobre a superfície do pavimento, com a finalidade de rejuvenescer o revestimento asfáltico, restabelecer o coeficiente de atrito pneu-pavimento, selar trincas com pequena abertura, impedir a entrada de água na estrutura do pavimento e retardar o desgaste causado por intemperismo.

- Recuperação de afundamento / ondulação / escorregamento / exsudação: A fresagem e o recapeamento são métodos geralmente utilizados na recuperação de afundamento plástico e de consolidação, também sendo empregados na recuperação de ondulações, escorregamento e exsudação. De acordo com Rocha (2010), o recapeamento é a construção de uma ou mais camadas asfálticas sobre o pavimento já existente, incluindo, geralmente, uma camada para corrigir o nivelamento do pavimento antigo, seguida de uma camada com espessura uniforme. Já a fresagem consiste na operação de corte do revestimento asfáltico, para restauração superficial do pavimento ou para melhorar sua capacidade de suporte (BERNUCCI, 2008).

- Recuperação de Buracos: A recuperação de buracos é geralmente feita por remendos, desde que bem executados. Caso o buraco seja encontrado em pequena proporção, a restauração será superficial, em outras situações, caso atinja a base, sub-base ou subleito, deverá ser profundo GONÇALVES, (1999). 
Seguindo a NORMA DNIT 154/2010, caso seja uma recuperação parcial, será feita a aplicação de um novo pavimento asfáltico, se for uma recuperação profunda, serão aplicados materiais granulares e betuminosos em todas as camadas do pavimento.

- Recuperação de remendos:Para realizar a restauração do pavimento, é necessário remover o remendo antigo, que foi feito de forma errada, e executar um novo, seguindo as normas DNIT 144/2010-ES, DNIT 145/2010ES, DNIT 153/2010-ES.

- Recuperação de desgaste: Em situações que houverem desgastes, a recuperação vai depender da intensidade. Caso seja baixa, utilizar-se-á lama asfáltica, porém deve-se analisar a estrutura do pavimento. Caso o pavimento esteja com a estrutura muito comprometida, deverá ser feita a remoção do pavimento e reconstrução da base, sub-base, e uma repavimentação, sendo um procedimento semelhante ao utilizado em buracos.

\section{RESULTADOS}

Na Via Regional, devido aos seus inúmeros defeitos que em sua grande maioria são: Trincas em malha, buracos, remendos, foi dado a solução de ser refeito toda a parte estrutural do solo, deixando com características uniforme e resistência requerida no projeto. Além de ser colocada uma nova camada de pavimento flexível, afim de resolver outros problemas existentes na via, como: ondulações, exsudação e o desgaste, que é o mais comum devido ao tempo e passagem constante de veículos.

\subsection{Principais defeitos na via regional}

- Em toda a extensão, a Via regional apresenta a trica em malha tipo "couro de jacaré" (Figura 3), mostrando que estas trincas já estão em estágio avançado.

Figura 3 - Trinca em malha tipo "couro de jacaré"

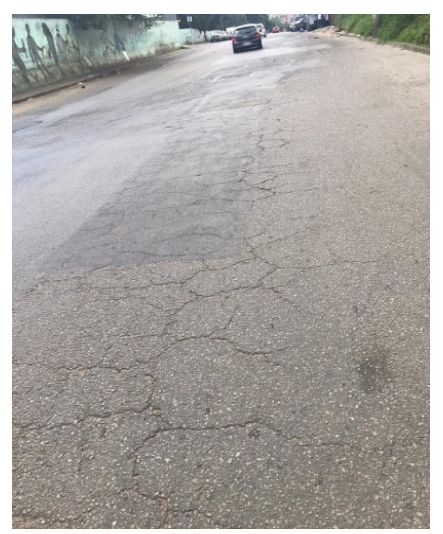

Fonte: Autor,2019

- Os buracos (Figura 4) também estão presentes em toda a via, e em grandes quantidades e em diferentes níveis de degradação, que provavelmente foram em decorrência de outras patologias. 
Figura 4 - Buraco

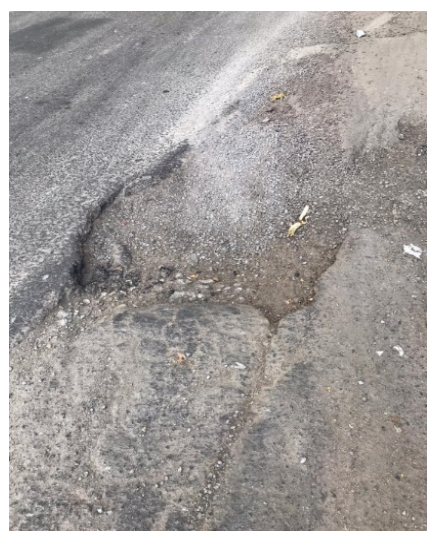

Fonte: Autor, 2019

- Os remendos (Figura 5) são constantes na Via Regional, pois sempre foi e é utilizado como principal forma de resolver as patologias e manter a integridade da via para que possa ser utilizada.

Figura 5 - Remendo antigo e remendo sendo feito.

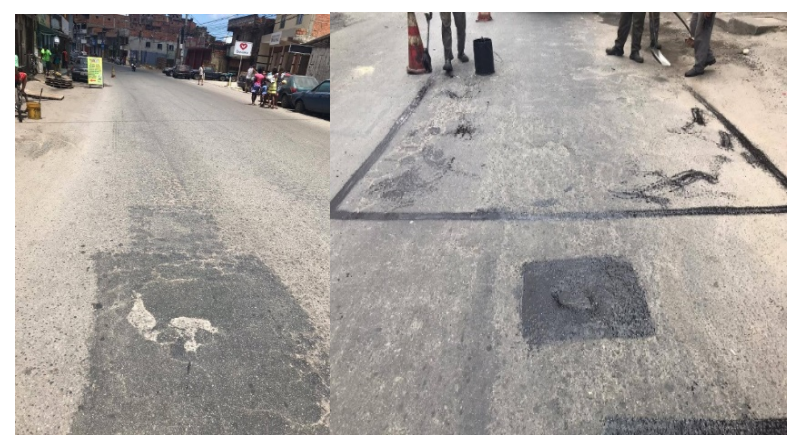

Fonte: Autor, 2019

- As ondulações (Figura 6) são vistas em várias partes da via, causando desconforto para os usuários da via.

Figura 6 - Ondulações com grande extensão na via.

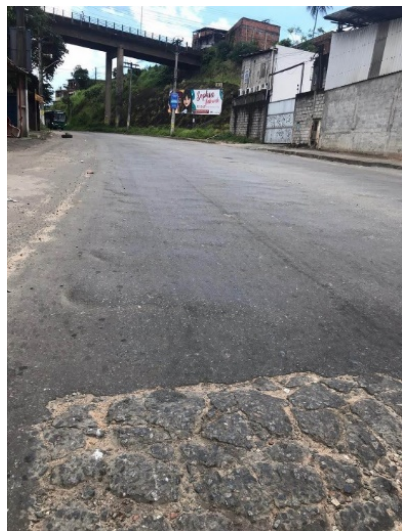

Fonte: Autor, 2019 
- A exsudação (Figura 7) foi encontrada em apenas um pequeno trecho da Via Regional, seguido por trincas em malha do tipo "couro de jacaré".

Figura 7 - Exsudação aparente na via.

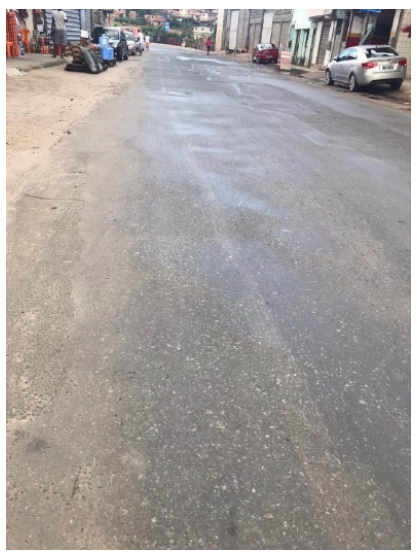

Fonte: Autor, 2019

- Os desgastes (Figura 8) na Regional são constantes, pois a mesma já é antiga e não teve grandes reformas. É nítido em todo a via, a presença desta patologia, além de perceber o agregado solto na pista.

Figura 8 - Desgaste: diferença entre um pavimento mais recente e um pavimento antigo.

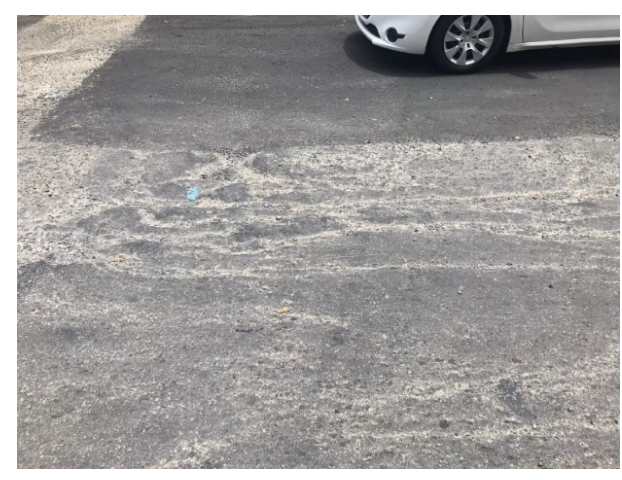

Fonte: Autor, 2019

Os defeitos apresentados nas Figuras 4 e 6 evidenciam a necessidade de intervenção estrutural do pavimento. A medida a ser adotada principalmente nesse caso deve ser a restauração completa das camadas de reforço do sub-leito, sub-base, base e revestimento, visto que, estas camadas já foram afetadas pela ação de intempéries e não apresentam mais sua resistência de projeto.

Já as figuras 3, 5, 7 e 8, apresentam defeitos que necessitam reconstituição da camada de revestimento, seguida de monitoramento das camadas inferiores, devido sua profundidade não atingir as demais camadas da superestrutura.

\section{CONCLUSÃO}

Com base no levantamento e estudos sobre as patologias nos pavimentos flexíveis, foi agregado conhecimento teórico, onde, o estudo do solo, é essencial para uma boa vida útil do pavimento flexível, pois a boa preparação e reforço do solo, evita problemas futuros ao asfalto, evitando problemas recorrentes do próprio pavimento. Sua execução, deve 
seguir a NORMA DNIT 031/2004-ES, que diminuirá o número de patologias, mas para que isso seja efetivo, é necessário que sejam feitos os reparos periódicos. Assim, aumentando a vida útil e prevenindo o aparecimento de patologias mais complexas.

Nesse estudo de caso, a base teórica, dá informação suficiente para que possam ser feitas análises superficiais e ajude nas tomadas de decisões iniciais, auxiliando nos diagnósticos rápidos de qualquer patologia em pavimento flexível.

Soluções para vias que necessitam de reforços estruturais, assim como a Via Regional, que tem maior grau de complexidade, necessitam de uma avaliação mais criteriosa, onde serão necessários equipamentos e estudos laboratoriais, que irão avaliar os problemas nos pavimentos flexíveis e solo, disponibilizando melhores informações e facilitando na especificação de qual a melhor solução para o problema. Verificando a necessidade de reforços, movimentações de terra e outras intervenções. Em recomendação, os estudos sobre as patologias e suas soluções devem ser mais abrangentes, pois envolve outros quesitos, tais como: qualidade do pavimento, formas de execução e a parte financeira, que são extremamente importantes para uma melhor avaliação e execução de projetos de recuperação.

\section{REFERÊNCIAS}

BERNUCCI et al, L.B. et al. Pavimentação Asfáltica: Formação básica para engenheiros. 1.ed. Rio de Janeiro: Petrobras ABEDA, 2008.

BRASIL. Departamento Nacional de Infraestrutura de Transporte. DNIT 031/2004 - ES: Pavimentos flexíveis Concreto asfáltico - Especificação de serviço. Rio de Janeiro, 2004.

BRASIL. Departamento Nacional de Infraestrutura de Transporte. DNIT 005/2003 - TER: Defeitos nos pavimentos flexíveis e semi-rígidos - Terminologia. Rio de Janeiro, 2003.

BRASIL. Departamento Nacional de Infraestrutura de Transporte. DNIT IPR/720: Manual de restauração de pavimentos asfálticos. Rio de Janeiro, 2006.

BRASIL. Departamento Nacional de Infraestrutura de Transporte. DNIT 144/2014-ES: Pavimentação - Imprimação com ligante asfáltico Especificação de serviço. Rio de Janeiro, 2014.

BRASIL. Departamento Nacional de Infraestrutura de Transporte. DNIT 145/2012 - ES: Pavimentação - Pintura de ligação com ligante asfaltico - Especificação de serviço. Rio de janeiro, 2012.

BRASIL. Departamento Nacional de Infraestrutura de Transporte. DNIT 153/2010 - ES: Pavimentação asfáltica - Prémisturado a frio com emulsão catiônica convencional - Especificação de serviço. Rio de janeiro, 2010.

GONÇALVES, P. F. O diagnóstico e manutenção dos pavimentos: (Notas de Aulas). 1999IBP - “As Emulsões Asfálticas e suas Aplicações Rodoviárias”. Rio de Janeiro, 1983.

RÉUS, T. F.; SILVA JÚNIOR, C. A. P.; FONTENELLE, H. B. Efeito do excesso de peso dos veículos comerciais de carga a partir de uma análise empírico-mecanística - Revista CIATEC - UPF, vol.8 (2), p.p.50-61, 2016

ROCHA, R.S. Patologias de pavimentos asfálticos e suas recuperações: estudo de caso da Avenida Pinto de Aguiar. Salvador, 2010 .

PINTO, J. I. B. R. Caracterização superficial de pavimentos rodoviários. 2003. Dissertação (Mestrado em Vias de Comunicação) - Programa de Pós-Graduação em Engenharia Civil, Universidade do Porto, Porto, 2003.

SILVA, P. F. A. Manual de patologia e manutenção de pavimentos. 2. ed. São Paulo: Pini, 2008. 128 p. 